\title{
ARTICLE/JOURNAL REVIEW
}

\section{Acknowledgements}

The authors express their sincere gratitude to the staff of the Women and Children's Hospital who tirelessly support all initiatives enhancing women's health care across Hull and East Yorkshire.

\section{Statements on funding and competing interests}

Funding. The pilot project was funded by four local primary care trusts through joint commissioning.

Competing interests. None identified.

References

1 Royal College of Obstetricians and Gynaecologists (RCOG). The Care of Women Requesting Induced Abortion (National EvidenceBased Clinical Guideline No. 7). London, UK: RCOG Press, 2004.

2 Department of Health. National Strategy for Sexual Health and HIV. London, UK: Department of Health, 2001.

3 The 'Economics of Sexual Health' research by Newcastle University, commissioned by fpa. 2005. http://www.fpa.org.uk/news/policy/PDFs/ Theeconomicsofsexualhealth.pdf [Accessed 19 September 2005]

4 Mackay HT, Schulz KF, Grimes DA. Safety of local versus general anaesthesia for second trimester dilatation and evacuation abortion. Obstet Gynecol 1985; 66: 661-665.

5 Grimes DA, Schulz KF, Cates W Jr, Tyler CW. Local versus general anaesthesia: which is safer for performing suction curettage abortion. Am J Obstet Gynecol 1979; 135: 1030-1035.

6 Lawson HW, Frye A, Atrash HK, Smith JC, Shulman HB, Ramick M. Abortion mortality, United States, 1972 through 1987. Am J Obstet Gynaecol 1994; 171: 1365-1372.

7 Thonneau P, Fougeyrollas B, Ducot B, Boubilley D, Dif J, Lalande $\mathrm{M}$, et al. Complications of abortion performed under local anesthesia. Eur J Obstet Gynecol Reprod Biol 1998; 81: 59-63.

8 Edward J, Creinin MD. Early abortion: surgical and medical options. Curr Prob Obstet Gynecol Fertil 1997; 20: 6-32.

9 Westfall JM, Sophocles A, Burggraf H, Ellis S. Manual vacuum aspiration for first-trimester abortion. Arch Fam Med 1998; 7: $559-562$.

10 Dean G, Cardenas L, Darney P, Goldberg A. Acceptability of manual versus electric aspiration for first trimester abortion: a randomized trial. Contraception 2003; 67: 201-206.

11 Hamoda H, Flett GM, Ashok AW, Templeton A. Surgical abortion using manual vacuum aspiration under local anaesthesia: a pilot study of feasibility and women's acceptability. J Fam Plann Reprod Health Care 2005; 31: 185-188.

12 Guthrie K, Waudby C, Arnott P. A termination of pregnancy care pathway: worth the effort? Eur J Contracept Reprod Health Care 2004; 9: 38 .

\section{Journal Review}

Efficacy of a new low-dose oral contraceptive with drospirenone in premenstrual dysphoric disorder. Yonkers KA, Brown C, Pearlstein TB, Foegh M, Sampson-Landers C, Rapkin A. Obstet Gynecol 2005; 106: 492-501

This multicentre, double-blinded, randomised, placebo-controlled trial in the USA aimed to assess the effect of a 24/4 regimen of drospirenone $3 \mathrm{mg}$ and ethinylestradiol $20 \mu \mathrm{g}$ on symptoms associated with premenstrual dysphoric disorder.

A total of 3496 women were recruited via advertisement and referral, with 450 being blindly randomised to receive either placebo or drospirenone/ethinylestradiol therapy over a 3month period. A high proportion of initially selected patients either discontinued the study prematurely or did not meet inclusion criteria. Seventy-one patients in the treatment group discontinued the study prematurely with over half complaining of adverse drug events. These included intermenstrual bleeding, headache and nausea.

Response to therapy was measured by daily self-assessment using the Daily Record of Severity of Problems Scale. Data were analysed from the intent-to-treat cohort that included all randomised subjects who took at least one treatment dose. Response to treatment was defined as a $50 \%$ reduction in daily symptom score. This occurred in $48 \%$ of the active treatment group and $36 \%$ of the placebo group (RR 1.7). This was significant at the $p<0.05$ level but not at $p<0.01$. This corresponded to a number-needed-to-treat of eight patients.

Although the results suggest that this new low-dose 24/4 regimen of drospirenone $3 \mathrm{mg}$ and ethinylestradiol $20 \mu \mathrm{g}$ is beneficial in symptom amelioration in premenstrual dysphoric disorder, a comparison was not made with either a standard combined oral contraceptive pill or with the currently marketed $21 / 7$ regimen of drospirenone $3 \mathrm{mg}$ and ethinylestradiol $30 \mu \mathrm{g}$ (under the trade name of Yasmin ${ }^{\circledR}$ ). The study was funded by the pharmaceutical company that supplies the trial drug, and two of the authors were employees of the company.

The cost effectiveness of low-dose drospirenone and ethinylestradiol therapy has yet to be evaluated and its relative efficacy compared to current treatment will need to be proven before such treatment becomes commonplace in the UK.

Reviewed by Karen Rose, MB ChB

Senior House Officer, Dean Terrace Family Planning Clinic, Edinburgh, UK

Impact on contraceptive practice of making emergency hormonal contraception available over the counter in Great Britain: repeated cross-sectional surveys. Marston C, Meltzer H, Majeed A. BMJ 2005; 331: 271-275

This paper compares data on contraceptive practice among 16-49-year-old women over 3 years from 2000 to 2002. Approximately 2000 women were surveyed each year as part of the Omnibus multipurpose survey. Women were selected by random sampling of addresses and occupants throughout the UK. Interviewers asked about use of contraceptives and emergency hormonal contraception (EHC).

The most striking change was the source of emergency contraception. The introduction of over-the-counter (OTC) EHC in January 2001 resulted in a marked increase in the proportion of women obtaining EHC from pharmacies (19.7\% in 2001 and $32.6 \%$ in 2002). There was a corresponding reduction in the proportion supplied from general practice and family planning clinics but little change in supply from emergency departments. Women who bought OTC EHC tended to be older, wealthier and single. Over the same period, the proportion of women using emergency contraception once or more than once a year remained static at approximately $6 \%$ and $2 \%$, respectively. There was no significant change in the proportion using reliable contraceptive methods or having unprotected intercourse. The authors conclude that availability of OTC EHC has not led to increased use or encouraged unsafe sex.

The survey did not determine the absolute number of times EHC was used and it excluded women under the age of 16 years. Although the authors attempted to correct for selection bias, they were unable to correct for non-response and recall bias. It was assumed that all EHC obtained from pharmacies was bought, with no mention of free supply under patient group direction. Thus the effect of OTC availability may have been underestimated. The study by Lloyd and Gale in the October 2005 issue of this journal showed an ncrease in EHC use in a rural setting since it became available OTC.

The impact on numbers of unplanned pregnancies is unknown, but OTC EHC does at least appear to be saving health service time and resources.

Lloyd K, Gale E. Provision of emergency hormonal area. J Fam Plann Reprod Health Care 2005; 31: 297-300.

Reviewed by Louise Melvin, MRCOG, DFFP Specialist Registrar, Simpson's Centre for Reproductive Health, Edinburgh, UK

Bleeding patterns after immediate initiation of an oral compared with a vaginal hormonal contraceptive. Westhoff C, Osborne LM, Schafer JE, Morroni C. Obstet Gynecol 2005; 106: 89-96

This study compared 84-day bleeding patterns of 201 women randomly assigned to immediate start ('Quick Start') of a triphasic oral contraceptive pill (25 $\mu \mathrm{g}$ ethinylestradiol) compared with the contraceptive vaginal ring (providing $15 \mu \mathrm{g}$ ethinylestradiol daily). The women either took their first pill or were fitted with a contraceptive vaginal ring irrespective of where they were in their cycle. They then used barrier contraception for the first 7 days and were asked to record their bleeding patterns on a daily basis. The mean bleeding-spotting days in the 84-day reference period for all women was 19.2 days (17.0 days for ring users and 21.4 days for pill users). As well as confirming the excellent bleeding pattern results found in earlier non-randomised studies for the contraceptive vaginal ring, this study also showed that the 'Quick Start' approach is an acceptable alternative to waiting for menses for both contraceptive methods. This is an important observation as this method is easy to implement, increases initiation and may increase effective use and continuation of contraception. Perhaps we should completely abandon the conventional advice we give to women about starting hormonal contraception 'after your next period'?

Reviewed by Andrew Horne, PhD, MRCOC AAGL Clinical Fellow in Gynaecological Endoscopy, Sunnybrook and Women's College Health Sciences Centre, Toronto, Canada 